\title{
Candidate Gene Polymorphism vis-a-vis Immune Response to Important Infectious Diseases in Bovines
}

\author{
Sushil Kumar*, Ran Vir Singh, Anuj Chauhan, Arvind Sonwane and Subodh Kumar
}

Indian Veterinary Research Institute, Izatnagar, Bareilly, Uttar Pradesh, India

*Corresponding author

\section{A B S T R A C T}

\begin{tabular}{|c|c|}
\hline & \multirow{6}{*}{$\begin{array}{l}\text { Infectious diseases have major adverse effects on livestock production, both in terms of } \\
\text { economics and on animal welfare. } 10-25 \% \text { loss in milk production efficiency has been } \\
\text { reported in tuberculosis infected animals. Udder infections alone account for annual } \\
\text { economic loss of Rs. } 6053.21 \text { crores incurred by dairy industry in India. Similarly } 10-25 \% \\
\text { loss in milk production efficiency has been reported in tuberculosis infected animals. } \\
\text { While traditional control measures such as vaccination, treatment and eradication exist, } \\
\text { improving the genetic resistance to diseases among livestock populations is an effective } \\
\text { alternate strategy as genetic gain is cumulative and permanent. Estimates of the heritability } \\
\text { for susceptibility to Bovine Tuberculosis (BTB), MAP infection, Somatic Cell Count } \\
\text { (SCC) were 0.18, 0.16 and } 0.11 \text { respectively demonstrating genetic variation for } \\
\text { susceptibility to various infections in dairy cattle. In livestock, a number of candidate } \\
\text { genes coding for proteins with very specific and unique roles in immune responses are } \\
\text { potential strong candidates for investigating genetic basis of disease resistance have been } \\
\text { investigated on the basis of their association to resistance or susceptibility in certain other } \\
\text { diseases and their known role in disease pathogenesis. The advancement in marker } \\
\text { research has potential implications in future selection programs if integrated with the } \\
\text { complete genetic variant details and production traits of the herd. }\end{array}$} \\
\hline Keywords & \\
\hline $\begin{array}{l}\text { Candidate gene, } \\
\text { Genetic marker, } \\
\text { Resistance, Disease, } \\
\text { Cattle. }\end{array}$ & \\
\hline Article Info & \\
\hline $\begin{array}{l}\text { Accepted: } \\
\text { 12 July } 2018 \\
\text { Available Online: } \\
10 \text { August } 2018\end{array}$ & \\
\hline & \\
\hline
\end{tabular}

\section{Introduction}

Livestock sector play an important role in socio economic development and the national economy of the country. With an overall contribution of $\sim 4 \%$ to GDP, livestock sector play an important role in national economy whilst contributing to the nutrition security, household income along with generating gainful employment in the rural areas, particularly among the landless, small and marginal farmers. India's livestock sector is one of the largest in the world and boasts of a huge array of animal genetic resource. As per the $19^{\text {th }}$ Livestock Census-2012, India is home to a total of 512.05 million livestock population comprising cattle, buffalo, sheep, goat, pig, horse and ponies, mules, donkeys, camels, mithun and yak. India ranks first in milk production, accounting for $18.81 \%$ of world production, achieving an annual output of 165.4 million tonnes during 2016-17 
(Economic Survey, 2016-17). However livestock productivity and farmers' profits are hampered due of prevalence of several infectious diseases that causes huge economic losses through morbidity and mortality. Improvement in milk production in past few decades has not necessarily resulted in proportionate increase in profits to dairy farmers. In spite of government's efforts to provide veterinary services through a network of physical and human infrastructure; infectious diseases continue to hamper production and productivity of livestock. Prevalent common methods of controlling infection are based on culling of the infected animals, quarantine, vaccination and administration of drugs either therapeutically or prophylactically to a large percentage of population, and control of the movements of the animal and/or animal products (Mantur and Amarnath, 2008; Blasco, 2010). However, these procedures have inherent shortcomings like increased production costs, and indiscriminate use of prophylactic antibiotics. Further it may trigger the development of antibiotic resistant strains which could lead to more complicated public health problems. In such a case, genetic resistance for disease opens a new window to alleviate the problem. Genetic resistance is the inherent capacity of a host to resist disease when exposed to pathogens, without prior exposure or immunization. A strategy that can be applied to combat infections is to identify cattle which are comparatively resistant/ tolerant to the diseases and delineate the inherent genetic differences in immune response at molecular level. Genetic improvement of disease resistance is a slow, long term process but it could reduce costs incurred in isolation, treatment, and culling of diseased animals. This review highlights the investigations carried out in genes which code for proteins with very specific and unique roles in immune responses against Brucellosis, Tuberculosis, Paratuberculosis,
Mastitis, FMD and other infections as potential strong candidates for investigating genetic basis of disease resistance.

\section{Presence of genetic variation to infectious diseases in bovines}

Genetic variation in susceptibility to several infectious diseases has been observed in cattle. Estimates of the heritability for susceptibility to Bovine Tuberculosis (BTB), MAP infection, Somatic Cell Count (SCC) were $0.18, \quad 0.16$ and 0.11 respectively (Brotherstone et al., 2010, Hinger et al., 2008, Mrode et al., 1996) demonstrating genetic variation for susceptibility to various infections in dairy cattle. Between-breed differences have also been reported for several infectious diseases in livestock. Prevalence of bovine tuberculosis and severity of its pathology was reported higher in Bos taurus and crossbreds as compared to Bos indicus cattle (Ameni et al., 2007). Macrophages from Nellore breed were found more efficient to control Brucella abortus intracellular survival than Holstein (Macedo et al., 2013). Sahiwal calves were more resistant than Holstein dairy breed calves to tick-borne tropical theileriosis (Glass et al., 2005). These findings indicate the superiority of indigenous Bos indicus breeds over Bos taurus breeds for disease resistance trait. Prevalence of bTB and severity of its pathology was reported higher in Bos taurus and crossbreds as compared to Bos indicus cattle (Ameni et al., 2007). Particular pedigree lines of cattle were found to have greater and lesser susceptibility to the disease (Phillips et al., 2002). Estimates of the heritability of response to $M$. bovis PPD (purified protein derivative) in Irish herds was 0.2769, while heritability of bTB susceptibility in British herds was estimated as 0.18 (Bermingham et al., 2009, Brotherstone et al., 2010). These encouraging findings indicate a role for genetics in a wider 
risk management strategy. Genes, coding for proteins with very specific and unique roles in immune responses can serve as a useful tool in identifying resistant superior genotypes for the production of new resistant animal population (Allen et al., 2010, Bermingham et al., 2014, Tsairidou et al., 2014). Genes, coding for proteins with very specific and unique roles in immune responses are potential strong candidates for investigating genetic basis of disease resistance.

\section{Brucellosis}

Bovine brucellosis whose etiological agent is Brucella abortus is an important zoonotic disease characterized by abortion during the last trimester of pregnancy, which results in impaired fertility and decreased milk production in cows (Carvalho Neta et al., 2009). Candidate genes/SNPs of cytokines and innate immunity, SLC11A1 microsatellite association has been explored for association with bovine brucellosis. Adams and Templeton, 1998 reported that (GT)13 microsatellite allele at 3'UTR of SLC11A1 has significant association with the natural resistance to brucellosis in cattle. Barthel et al., (2001) showed that (GT) 13 allele restricted the intracellular replication of Brucella organisms using an in vitro macrophage challenge study. On the contrary, Kumar et al., 2005 and Paixao et al., (2007) demonstrated a lack of association of $3^{\prime}$ UTR polymorphisms with the resistance against bovine brucellosis. On the other hand, Capparelli et al., (2007a, 2007b) reported a significant association of polymorphisms at $3^{\prime}$ UTR of SLC11A1 gene with resistance/susceptibility to brucellosis in buffalo. Nevertheless, polymorphisms in other regions of SLC11A1 gene can serve as a potential marker (Liu et al., 1995; Abel et al., 1998; Bellamy et al., 1998). Additionally, Martinez et al. (2008a) identified novel polymorphisms in exons of the Slc11A1 gene, based on GenBank accession number
AC149748, and on information previously reported by Coussens et al. (2004). Further, TM4 is known to play an important role in positioning the NRAMP1 protein within the phagosomal membrane (Malo et al., 1994). Prakash et al., (2014) reported that SNPs of TLR4 gene, at TLR4 $(+10 \mathrm{C} / \mathrm{T})$ locus the frequency of ' $\mathrm{C}$ ' allele versus ' $\mathrm{T}$ ' was significantly higher in brucellosis positive cattle with its OR of 4.73. Similarly, TLR4 $(+399 \mathrm{C} / \mathrm{T})$ locus revealed that frequency of ' $\mathrm{C}$ ' allele versus ' $\mathrm{T}$ ' allele was significantly lower in affected cattle with its OR 0.13. Results also underscored the importance of cytokines and their receptors in conferring protection against brucellosis and warrant further functional characterization of these associations. Total three genotypes (GG, CG, $\mathrm{CC})$ were found at SLC11A1 (+1066 C/G) locus and were significantly differing in brucellosis affected cattle as compared to negative control cattle where the odds ratio of $\mathrm{CG}$ and $\mathrm{CC}$ genotypes versus GG genotype for were 0.31 and 0.18 . It indicated that GG genotype was responsible for susceptibility and $\mathrm{CC}$ genotype conferred resistance for brucellosis. At TLR1 (+1446 C/A) locus the odds ratio of $\mathrm{AC}$ genotype versus $\mathrm{CC}$ genotype was 0.24 in case (brucellosis) which revealed that relative proportion $\mathrm{CC}$ genotypes was significantly higher in case population than control population whereas, AA genotype was exclusively present in only one brucellosis positive animal and was totally absent in control population and its OR was towards infinity. It indicated that $\mathrm{CC}$ genotype at TLR1 (+1446 C/A) locus was responsible for increasing relative risk of bovine brucellosis and hence selection against CC genotype may reduce sero-prevalence of brucellosis in cattle.

\section{Bovine tuberculosis}

Bovine Tuberculosis is caused by $M$. bovis, which is an obligate aerobic, facultative intracellular parasite, usually of macrophages. 
Although cattle are considered to be the true hosts of $M$. bovis, the disease has been reported in many other domesticated and nondomesticated animals. Genes involved in recognition of components of Mycobacterium bovis and subsequent activation of both innate and adaptive immune response have been investigated as potential strong candidates for genetic basis of resistance. Polymorphisms of the SP110 nuclear body protein (SP110) gene have been reported to be associated with tuberculosis (Tosh et al., 2006). However in case of SNPs rs41256732 and rs134537150 of SP110 and SNPs rs137338039 and s208436798 of DC-SIGN gene, the genotype as well as allele had non-significant effect on occurrence of bovine tuberculosis (Baqir et al., 2015). At rs109915208 locus the genotypic as well as allelic frequencies were differing significantly in case-control animals where the odds ratio (OR) of ' $\mathrm{CC}$ ' verses ' $\mathrm{CT}$ ' genotype and the $\mathrm{OR}$ of ' $\mathrm{C}$ ' verses ' $\mathrm{T}$ ' allele were approaching towards infinity, suggesting that animals having ' $\mathrm{CT}$ ' genotype and ' $\mathrm{T}$ ' allele were less susceptible for tuberculin reaction as compared to their contemporary genotype/allele (Baqir et al., 2016). In TLR2 gene, two of SNPs under study (rs55617172 and rs68268253) revealed polymorphism while in the case of TLR4 gene all four SNPs under investigation (rs8193041, rs207836014, rs8193060, and rs8193069) were found to be polymorphic in case-control population. SNP locus rs55617172 in TLR2 gene was found significantly $\quad(p<0.01)$ associated with susceptibility/resistance to TB in cattle (Bhaladhare et al., 2016). Chauhan et al., 2016 reported that expression of candidate gene CXCR3 was significantly upregulated (5.22 fold) in PBMCs of $M$. bovis infected cattle vis a vis healthy controls. In TLR9 gene, SNP loci rs210982793 and rs207807011 were significantly associated with susceptibility to bovine tuberculosis in the case control population. At SNP locus rs210982793, probability values showed that the genotype $(\mathrm{P}=0.01)$ as well as allele $(\mathrm{P}$ $<0.01$ ) had significant effect on occurrence of bovine tuberculosis. The odds of CC and CT genotypes verses TT were close to zero, revealing that TT genotypes were relatively more resistant to bTB in comparison to other two genotypes. The OR of A verse $G$ was 0.27 revealing lower susceptibility of A allele with bTB in comparison to G allele at TLR9A1433G locus. The OR of AG versus GG was 0.19 which suggested that $A G$ genotype were less susceptible to tuberculosis as compared to GG. Both these SNPs loci were nonsynonymous, thus suggestive of their functional role in the immune response against bovine tuberculosis. (Bhaladhare et al.,2018). In an investigation on association between polymorphisms in TLR2 of Chinese Holstein cattle and susceptibility to bovine tuberculosis, the allele and genotype distributions of A631G (rs95214857) and T1707C (rs1388116488) were not different between case and control groups, indicated that these SNPs were not associated with susceptibility to BTB (Zhao et al., 2017). Using microarray analysis, Shukla et al., 2017 identified TLR2, CD80, NFKB1, IL8, CXCL6 and ADORA3 as putative candidate genes based on differential gene expression in Mycobacterium bovis challenged monocytederived macrophages of cattle. In study aimed to investigate the effect of four SNPs (G1793A, C1859A, A1980G, G1934A) in toll-like receptor 6 (TLR6) on bovine tuberculosis (bTB) resistance in Chinese Holstein cattle in a case-control study. Genotype frequencies of C1859A and A1980G site differed significantly between bTB-infected and non-infected cows. Relative risk of tuberculosis incidence result showed that genotypes of AA or CA had greater relative risk than those with genotype $\mathrm{CC}$ at C1859A site between bTB-infected and noninfected animals. Genotypes of GG or GA had greater relative risk than those with 
genotype AA at A1980G site. No significant association can be inferred from G1793A and G1934A polymorphism site. Significantly increased BTB susceptibility was evident in T allele carriers of $-5 \mathrm{C} / \mathrm{T}, \mathrm{G}$ allele carriers of 613G/A and TG haplotype carriers of both SNPs in the CD14 gene in Chinese Holstein cows. These results suggested that $-5 \mathrm{C} / \mathrm{T}$ and 613G/A are risk factors for BTB in Chinese Holstein cattle and might be used as candidate genetic markers in breeding cows with natural resistance to BTB (Xue et al., 2018). Casecontrol association testing and statistical analysis identified six SNPs associated with susceptibility to BTB in Chinese Holstein cows. The frequency of genotypes $\mathrm{C} / \mathrm{T}, \mathrm{A} / \mathrm{G}$, $\mathrm{A} / \mathrm{G}, \mathrm{A} / \mathrm{G}, \mathrm{C} / \mathrm{T}$, and $\mathrm{A} / \mathrm{G}$ in $\mathrm{E} 4(-37), 208$, 1644, 1648, 1799, and E10 (+107), respectively, was significantly higher in cases than in controls, and also the alleles C, A, A, $\mathrm{G}, \mathrm{T}$, and $\mathrm{A}$, respectively, were associated with a greater relative risk in cases than in controls. The distribution of two haplotypes, TGGACA and CAGACA, was significantly different between cases and controls. Overall, this case-control study suggested that E4 (37)(C/T), 208(A/G), 1644(A/G), 1648(A/G), $1799(\mathrm{C} / \mathrm{T})$, and $\mathrm{E} 10(+107)(\mathrm{A} / \mathrm{G})$ in the CARD15 gene were significantly associated with susceptibility to BTB in Chinese Holstein cows and that haplotypes TGGACA and CAGACA could be used as genetic markers in marker-assisted breeding programs for breeding cows with high resistance to BTB (Wang et al., 2018).

\section{Paratuberculosis}

Mycobacterium avium sub species paratuberculosis (MAP) is a facultative intracellular pathogen that causes Johne's disease (JD), a chronic granulomatous inflammation of the intestine characterized by persistent diarrhea, progressive wasting, and finally death. Loss due to reduced milk yields alone in case of Mycobacterium avium subspecies paratuberculosis (MAP) infected cows were reported to be Rs 54,442.5 /cow/lactation in India (Rawat et al., 2014). Reports are available about association study of bovine paratuberculosis with candidate gene polymorphism (Ruiz et al., 2007, Settle et al., 2009, Pinedo et al., 2009, Pant et al., 2010, Koets et al., 2010). Ruiz et al., (2007) reported that SNP N23 of Nramp1 (located in the BTA2 and comprises 15 exons) was genetically associated with resistance to the paratuberculosis infection $(\mathrm{P}=0.0478)$. Koets et al., (2010) reported that the TLR2-1903 T/C SNP was significantly associated with resistance to MAP where cows with CT and CC genotypes were at 1.7 (95\% CI: 1.2, 2.8) times the odds of being MAP infected compared to cows with the TT genotype. Pant et al., (2010) reported 22 SNPs on 7 different chromosomes significantly associated with the disease trait using this genome-wide threshold. Pinedo et al., (2009) characterize the distribution of polymorphisms in the bovine CARD15 gene and test their association with paratuberculosis infection in cattle. Pinedo et al., (2009) reported a significant association between infection status and BoIFNGSNP12781 and SLC11A1275-279-281 microsatellites. Verschoor et al., (2010) that SNPs in IL10RA are associated with MAP infection status in dairy cattle. Pant et al. (2011) reported four SNPs in IFNGR2, IL12RB1, IL12RB2, and IL23R were found to be associated with the MAP infection status of the resource population. In a case: control association study conducted in cattle using 20 SNPs selected from the cattle QTL database on the basis of the potential role in mycobacterium susceptibility, SNP (rs41945014) was significantly associated with MAP and revealed that ODDs of GG and GT genotypes verses TT genotype were 1.22 and 3.37 respectively. The proportion of GG and GT genotypes were significantly higher in bovine paratuberculosis positive animals suggested that selection against these 2 
genotypes may confer resistance against bovine paratuberculosis (Yadav et al., 2014). Chauhan et al., 2015 reported differential expression of candidate genes of Toll like Receptors and Interleukins family namely TLR2, IFN-ã, IL2, IL8 and TNF in Mycobacterium avium sub sp. Paratuberculosis infected cattle.

\section{Mastitis}

Genes associated with immune responses of mammary gland are potential genetic markers because of their importance in mastitis. Besides, genes associated with neutrophil function are potential genetic markers for mastitis, as neutrophil migration from blood to the sites of infection is essential for resolution of most mastitis pathogens (Paape et al., 2000). Non-significant associations were found between SNPs of cytokine genes (IFNG -639 T/C; IFNG +432 G/A; IFNGR1 +132 G/T; IFNGR1 +523 A/G) with somatic cell count and lactation persistency (Verschoor et al., 2012). Homozygous genotype at TLR4 (+2021 C/T) locus was found to be significantly associated with incidences of mastitis (JiaPeng et al., 2010). The polymorphisms in TLR4 $(+1656 \mathrm{C} / \mathrm{T})$ and TLR4 $(+2021 \mathrm{C} / \mathrm{T})$ loci were associated with estimated breeding values for lactation persistency, and somatic cell scores in the Canadian Holstein bull population (Sharma et al., 2006). Paswan et al., (2005) reported nonsignificant effect of HaeIII and Rsa I patterns/genotypes of BoLA DRB3.2 alleles on SCC and SCS in crossbred cows. Nonsignificant associations were found between SNPs of cytokine genes (IFNG -639 T/C; IFNG +432 G/A; IFNGR1 +132 G/T; IFNGR1 +523 A/G) with somatic cell count and lactation persistency. Yuan et al. 2012 reported the combined genotype analysis of three SNPs (G22231T, T25025A and C28300A in bovine BRCA1 gene) and showed association of BBDDFF genotype with the highest SCS that indicated mastitis susceptibility. However, AACCEE genotype associated with the lowest SCS was favorable for the mastitis resistance. Asaf et al. 2014 reported that single nucleotide polymorphism rs109231409 located on mannose-binding lectins 1 (MBL1) gene was not associated with mastitis tolerance/susceptibility. Asaf et al., (2015), reported polymorphism of the BRCA1 SNPs, i.e., G22231T but reported no significant association with mastitis susceptibility in Vrindavani cattle by PCRRFLP. Wang et al. 2007 reported A-G SNP at nucleotide 4525 in intron 1 of TLR4 gene and indicated that this variation might play an important role in bovine mastitis resistance.

Based on association with SCC, Ranjan (2014), detected significant marker allele affecting the incidence of mastitis for markers DIK20, BM3 02, BM4505, CYP21 and BMS2684 in crossbred cattle. Gupta based on association with SCS detected significant microsatellite marker allele effect on the incidence of mastitis for marker BM1818 and BM1443 in Vrindavani crossbred cattle. Associations between leptin genotypes and SCC have also been reported in dairy cattle (Buchanan et al., 2003). Kulig et al., (2010) reported that the $\mathrm{R} 4 \mathrm{C}$ and Sau3AI polymorphisms significantly affected SCC (P $\leq 0.01$ ) with $\mathrm{C}$ and $\mathrm{T}$ as a desirable allele, respectively. No associations were found between the A59V polymorphism and SCC in this study. However, all the genotype combinations (haplotypes) significantly affected this trait. The results indicate that selection for the R4C CC and Sau3AI TT animals might contribute to a reduction of SCC in Jersey cattle. Sequence comparison of buffalo with cattle reveals variation at five nucleotide sequences at positions 983, 1083, 1147, 1152, 1221 and all the SNPs are synonymous (Datta et al., 2012). Sulabh et al., 2018 reported that peptidoglycan and lipoteichoic acid induces differential mRNA response of immune-related TLR-2, TNF- $\alpha$, IL-8, IFN- $\gamma$ and IL-10 genes in PBMC of 
Crossbred, Tharparkar Cattle and Murrah Buffalo.

\section{FMD}

Lei et al., (2012) using PCR-RFLP with HaeIII enzyme reported that allele Hae III A was associated with susceptibility to FMD in Wanbei cattle whereas Hae III C was associated with resistance to FMD and may have a strong protective effect against FMD. Hae IIICC and Hae III BC genotype were associated with resistance to FMD. By contrast, Hae III AA genotype was associated with susceptibility to FMD $(\mathrm{P}<0.01)$. Sequence analysis show that 89 amino acids were translated in exon 2 of BoLA-DRB3 and $13.70 \%$ of nucleotide mutated, which resulted in $14.61 \%$ of amino acid change. It indicated that Wanbei cattle had the ability of resistance to disease by mutation which result changes of the protein structure to perform the regulation of the cell using different signaling pathways in the long process of choice evolution. Gowane et al., (2013) reported that DRB3 alleles 0201, 0801 and 1501 always ranked high for protective immune response whereas alleles 0701, 1103 and 1101 consistently ranked low for unprotected immune response for all the three serotypes of FMDV in crossbred cattle vaccinated for footand-mouth disease. Chinsangaram et al., (2003) reported the IFN- $\alpha / \beta$ is an ideal candidate for rapid induction of FMDV resistance in animal. Singh et al., (2014) concluded that SNP G29A mutation in the 5 UTR of the ITGB6 gene (chromosome 2) associated with resistance to FMD infection in the zebu cattle.

\section{Reports in other infections and immune response parameters}

In bovines, bovine MHC (BoLA)-DRB gene had been implicated in the resistance and susceptibility to a broad range of diseases
(Rupp et al., 2007). MHC classes II BoLADRB3.2 genes polymorphic were correlated with resistance and susceptibility to the development of persistent lymphocytosis (PL) cased by bovine leukaemia virus (BLV) infection in cattle (Xu et al., 1993, Zannoti et al., 1996). Panei et al., (2009) identified 17 BoLA-DRB3 alleles defined according to the PCR-RFLP nomenclature and represented the distribution of the allele frequent in HolandoArgentino dairy cattle. Alleles BoLADRB3.2*11, $* 23$ and $* 28$ mediating resistance to PL and alleles BoLADRB3.2*22 and $* 24$ mediating susceptibility to PL were observed, alleles BoLADRB3.2*25 and *40 also showed signification association to PL. The DRB3 polymorphism has also been observed to be associated with resistance or susceptibility to dermatophilosis, cystic ovarian and mastitis (Maillard et al., 1999, 2001, Nassiry et al., 2005). Martinez et al., (2006) reported BoLADRB3.2 (Chromosome 23) alleles association between BoLA marker-DRB 3.2allele, 18, 20, and 27 for lower tick numbers in a reference Holstein $\times$ GYR F2 population in Brazil can be used to help in the selection of animals resistant to tick infestation. Rodriguez et al., (2005) reported that the allele 128bp of DRBP1 locus and allele $152 \mathrm{bp}$ of BM1815 may be involved in susceptibility to tick infestation in Holstein $\times$ Zebu animals. As a criterion of innate immunity development, Chaudhary et al., (2016) reported that levels of IgG in buffalo colostrums (before first milking) estimated by Indirect ELISA ranged from 11.22 to $185.1 \mathrm{mg} / \mathrm{ml}$ and mean IgG concentration in colostrum was $51.71 \pm 5.99$ $\mathrm{mg} / \mathrm{ml}$. In beta 2 microglobulin $(\beta 2 \mathrm{M})$, a structural gene which acts as an integral component of FcRn (neonatal $\mathrm{Fc}$ receptor) heterodimer for its cell surface expression, two insertions and one deletion of nucleotides in the intronic and exonic regions of $\beta 2 \mathrm{M}$ gene in buffalo were observed in comparison to $\beta 2 \mathrm{M}$ gene of cattle. (Chaudhary et 
al.,2016). The least square analysis of variance revealed a non-significant effect of dam $\beta 2 \mathrm{M}$ haplotype on IgG concentrations in colostrums (Chaudhary et al., 2018). Similar non significant association between $\beta 2 \mathrm{M}$ haplotypes in buffalo calves with serum IgG concentration was also observed by Rajani et al., (2016). Chauhan et al., 2015 reported differential expression profile of innate immune response genes including TLR2, NFKB1, TNF, IFNG, IL2, CXCR3, PRKCB1, RPS6KB2, STK17B and EEF1. Mishra et al., (2018) identified single nucleotide polymorphisms in 5' upstream region of bovine TLR4 gene affecting expression profile and transcription factor binding sites. These findings in TLR4 gene offer essential evidence that can be useful in future research exploring its role in immunity and TLR4 can be used as a marker for selection for disease resistance in bovines.

\section{References}

Abel, L., Sanchez, F. O., Oberti, J., Thuc, N. V., Hoa, L. V., Lap, V.L., Skamene, E., Lagrange, P.H. and Schurr, E. 1998. Susceptibility to leprosy is linked to the human NRAMP1 gene. J. Infect. Dis. 177:133-145.

Adams, L. G. and Templeton, J. W. 1998. Genetic resistance to bacterial diseases of animals. Rev. Sci. Tech. 17:200219.

Allen AR, Minozzi G, Glass EJ, Skuce RA, McDowell SW, Woolliams JA, Bishop SC.2010. Bovine tuberculosis: the genetic basis of host susceptibility. Proc Biol Sci. 2010 Sep 22; 277(1695):2737-45. Epub 2010 Jun 2. Review. PubMed PMID: 20519223; PubMed Central PMCID: PMC2981996.

Ameni, G., Aseffa, A., Engers, H., Young, D., Gordon, S., Hewinson, G., and M. Vordermeier. 2007. Both prevalence and severity of pathology of bovine tuberculosis are higher in Holsteins than in Zebu breeds under field cattle husbandry in central Ethiopia. Clin. Vaccine Immunol. 14(10):1356-61.

Asaf, M.V.N., Bhushan, B., Panigrahi, M., Dewangan, P., Kumar, A., Kumar, P. and Gaur, G.K. 2014. Association study of genetic variants at single nucleotide polymorphism rs109231409 of mannose-binding lectins 1 gene with mastitis susceptibility in Vrindavani crossbred cattle. Vet. World. 7(10): 807-810.

Asaf, V.N., Bhushan, B., Panigrahi, M., Kumar, A., Dewangan, P., Gaur, G.K. and Sharma, D. 2015. Lack of association of allelic variants of BRCA1 gene with mastitis susceptibility in Vrindavani cattle. Indian J. Anim. Sci. 85(1): 81-83.

Baqir, M., Bhushan, B., Kumar, S., Sonawane, A., Singh, R., Chauhan, A., Yadav, R., Prakash, O., Renjith, R., Baladhare, A. and Sharma, D. 2016. Association of polymorphisms in SLC11A1 gene with bovine tuberculosis trait among Indian cattle. Journal of Applied Animal Research. 44(1): 380-383.

Baqir, Mohd., Bhusan, Saket., Kumar, Amit., Chauhan, Anuj., Sonwane, Arvind., Kumar, Pushpendra., Yadav, Ramji., Shukla, Kumar, Sanjeev., Maurya, Sandeep., Maurya, Raj Veer and Sharma, Deepak. 2015. Association of Single Nucleotide Polymorphisms in the DC-SIGN and SP110 Genes with Bovine Tuberculosis in Cattle. Journal of Pure and Applied Microbiology. 9 (Special Edition): 119-125.

Baqir, Mohd., Bhusan, Saket., Sharma, Deepak., Kumar, Amit., Saminathan, M., Dhama, K., Bhaladhare, Ashish., Yadav, Ramji., Prakash, Om., Renjith, R., Sonwane, Arvind., Kumar, 
Pushpendra and Chauhan, Anuj. 2014. Bovine IL12RB1, IL12RB2, and IL23R Polymorphisms and Bovine Tuberculosis? (bTB) Infection status. Journal of Pure and Applied Microbiology. 8(5): 4117-4124.

Barthel, R., J. Feng, J. A. Piedrathia, D. N. McMurray, J. W. Templeton and L. G. Adams. 2001. Stable transfection of the bovine NRAMP1 gene into murine RAW264.7 cells: Effect on Brucella abortus survival. Infect. Immun. 69:3110- 3119.

Bellamy, R., C. Rumende, T. Corrah, K. P. W. J. McAdam, H. C. Whittle and A. V. S. Hill. 1998. Variation in the human NRAMP1 gene and susceptibility to tuberculosis on Africans. New Engl. J. Med. 338:640644.

Bermingham, M, L., More, S.J., Good, M., Cromie, A.R., Higgins, I.M., 2009. Genetics of tuberculosis in Irish Holstein-Friesian dairy herds. J Dairy Sci. 92:3447-3456.

Bermingham, M.L., Bishop S.C., Woolliams J.A. et al. (2014) Genome-wide association study identifies novel loci associated with resistance to bovine tuberculosis. Heredity 112, 543-51.

Bhaladhare, A., Sharma, D., Kumar, A., Sonwane, A., Chauhan, A., Singh, R., Kumar, P., Yadav, R., Baqir, M., Bhushan, B., Prakash, O., 2016. Single nucleotide polymorphisms in toll-like receptor genes and casecontrol association studies with bovine tuberculosis, Veterinary World. 9(5): 458-464.

Bhaladhare, Ashish., Sharma, Deepak., Chauhan, Anuj., Kumar, Amit., Sonwane, Arvind., Singh, R. V., Kumar, Pushpendra., Kumar, Subodh and Bhushan, Bharat. 2018. Association study of Single Nucleotide Polymorphisms (SNP) in
Toll-like Receptor 9 gene with bovine tuberculosis. Indian J. Anim. Res. 52(4):533-537.

Blasco, J.M. 2010. Control and eradication strategies for Brucella melitensis infection in sheep and goats. Prilozi. 31(1):145-65.

Brotherstone, S., White, I. M. S., Coffey, M., Downs, S. H., Mitchell, A. P., ClftonHadley, R. S., More, S. J., Good, M. and J.A. Woolliams. 2010. Evidence of genetic resistance of cattle to infection with Mycobacterium bovis. J. Dairy Sci. 93: 1234-1242.

Buchanan, F.C., Van, Kessel, A.G., Waldner, C., Christensen, D,A., Laarveld, B., Schmutz, S.M. 2003. Hot Topic: An association between a leptin single nucleotide polymorphism and milk and protein yield. J Dairy Sci. 86: 3164-3166.

Capparelli, R., Alfano, F., Amoroso, M. G., Borriello, G., Fenizia, D., Bianco, A., Roperto, S., Roperto, F. and Iannelli, D. 2007a. Protective effect of the Nramp1 BB genotype against Brucella abortus in water buffalo (Bubalus bubalis). Infect. Immun. 75: 988-996.

Capparelli, R., Borriello, G., Marabelli R. S., Roperto, F. and Iannelli, D. 2007b. The Nramp1 AA genotype confers susceptibility to Brucella abortus in water buffalo. Mamm. Genome. 18:137-143.

Carvalho Neta, A.V., Mol, J.P., Xavier, M.N. 2010. Pathogenesis of bovine brucellosis. Vet. J., 184:146-155.

Chaudhary, R., Kumar, S., Yathish, H.M., Mishra, C., Chauhan, A. and Sahoo, N.R. 2016. Estimation of immunoglobulin $\mathrm{G}$ levels in colostrum of Murrah buffaloes. International Journal of Science, Environment and Technology. 5(4): 2003-2007.

Chaudhary, Rajni., Kumar, Subodh., Yathish, HM., Sivakumar, A., Mishra, 
Chinmoy., Kumar, Amit., Chauhan, Anuj., Sivamani, B., Sahoo, N.R. Identification of SNPs in Beta 2 Microglobulin (b2M) Gene and their Association with IgG Concentration in Neonatal Buffalo Calves. 2016. Journal of Pure and Applied Microbiology. 10(2): 1387-1394.

Chaudhary, Rajni., Kumar, Subodh., Yathish, HM., Sivakumar, A., Mishra, Chinmoy., Kumar, Amit., Chauhan, Anuj., Sivamani, B., Sahoo, R. N. 2018. Nucleotide variability in Beta 2 Microglobulin $(\beta 2 \mathrm{M})$ gene and its association with colostral IgG levels in buffaloes (Bubalus bubalis). Indian J. Anim. Res. 52 (1): 51-55.

Chauhan, Anuj., Maurya, Sandeep., Shukla, Sanjeev., Kumar, Pushpendra., Sonwane, Arvind., Maurya, veer, Raj., Kumar, Subodh., Baranwal, Amit., Kumar, Sushil., Gopi., Bhushan, Bharat and Sharma, Deepak. 2016. mRNA Expression of Chemokine Genes in Bovine Tuberculosis Infected Crossbred Cattle. Journal of Pure and Applied Microbiology 10(3): 2283-2288.

Chauhan, Anuj., Maurya, Sandeep., Shukla, Sanjeev., Singh, Vir, Ran., Sonwane, Arvind., Prakash, Chandan., Maurya, Veer, Raj., Kumar, Pushpendra., Sarvjeet., Baranwal, Amit., Sharma, Deepak. and Bhushan, Bharat. 2015. Analysis of Toll like Receptors and Interleukins Expression Profile in Mycobacterium avium sub sp. paratuberculosis Infected Cattle. Journal of Pure and Applied Microbiology. 9 (Special Edition): 297-305.

Chauhan, Anuj., Maurya, Sandeep., Yadav, A.S., Sonwane, Arvind., Shukla, Kumar, Sanjeev., Prakash, Chandan., Kumar, Pushpendra., Singh, vir, Ran., Sarvjeet., Kumar, Subodh and
Sharma, Deepak. 2015. Differential Expression Profile of Innate Immune Response Genes between Indigenous and Crossbred Cattle. Journal of Pure and Applied Microbiology. 9 (4): 2913-2920.

Chinsangaram, J., Moraes, M.P., Koster, M. and Grubman, M.J. 2003. Novel viral disease control strategy: Adenovirus expressing alpha interferon rapidly protects swine from foot-and-mouth disease. J. Virol. 77(2): 1621-1625.

Coussens, P. M., M. J. Coussens, B. C. Tooker and W. P. Nobis. 2004. Structure of the bovine natural resistance associated macrophage protein (NRAMP 1) gene and identification of a novel polymorphism DNA Seq. 15(1):15-25.

Datta, Sanjoy., AMJB Adhikari., Chauhan, Anuj., Verma, Archana., Gupta, I. D., Chauhan, Inderasen., Azad, S. Mandeep and Yatish, H. M. 2012. Nucleotide Sequence Variation in Leptin Gene of Murrah Buffalo (Bubalus bubalis). Exploratory Anim. and Medical Res. 2(2): 130 - 36.

Department of Animal Husbandry, Dairying \& Fisheries Ministry of Agriculture, Government of India (2016-17): http://www.dahd.nic.in \& http://farmer.gov.in

Dige, Mahesh, Shivanand., Ahlawat, S. P. S., Kumar, Pushpendra., Chauhan, Anuj., Inamdar, B., Kokate, L. S. and Dutt, Triveni. 2013. Dissecting the Partial Genomic Region of CXCR to Correlate with CMT in Vrindavani Cattle. Indian Journal of Animal Research. 47(4): 335-339.

Dinesh, C. N., Sonawane, A., Kumar, Amit., R, Rana., Chauhan, A., Sharma, D. 2013. Effect of genetic and nongenetic factors on seroprevalence of Mycoplasma mycoides Subsp. capri in 
goat. Journal of Veterinary and Animal Sciences. 44: 38-41.

Glass, E.J., Preston, P.M., Springbett, A., Craigmile, S., Kirvar, E., Wilkie, G. and C. G. Brown. 2005. Bos taurus and Bos indicus (Sahiwal) calves respond differently to infection with Theileria annulata and produce markedly different levels of acute phase proteins. Int $\mathbf{J}$ Parasitol. 35(3): 337-47.

Gowane, G.R., Sharma, A.K., Sankar, M., Narayanan, K., Das, B., Subramaniam, S. and Pattnaik, B. 2013. Association of BoLA DRB3 alleles with variability in immune response among the crossbred cattle vaccinated for footand-mouth disease (FMD). Res. Vet. Sci. 95: 156-163.

Gupta, J.P. 2015. Microsatellite Analysis and Expression Profiling of Candidate Genes Associated with Mastitis in Crossbred Cattle. Ph.D. Thesis. IVRI (Deemed University), Bareilly, UP, India

Gupta, J.P., Bhushan, B., Panigrahi, M., Ranjan, S., Asaf, V.N.M., Kumar, A., Sulabh, S., Kumar, A., Kumar, P. and Sharma, D. 2015. Study on genetic variation of short tandem repeats (STR) markers and their association with somatic cell scores (SCS) in crossbred cows. Indian J. Anim. Res. 49(5): 595-598.

Hinger,M., Brandt, H. and G. Erhard. 2008. Heritability Estimates for Antibody Response to Mycobacterium avium subspecies paratuberculosis in German Holstein Cattle. 91(8):3237-3244.

Jia, Peng, L., Jie, B., Zhang, X., LiXin, T., ShengLin, J., WenRong, L., MingJun, L.2010. Association the mutation of 2021 locus of Toll-like receptor 4 gene (TLR4) exon III polymorphisms with somatic cell score in Xinjiang brown cattle. J Agri Biotechnol. 18:1115-1122.

Koets, A., Santema, W., Mertens, H., Oostenrijk, D., Keestra,M., Overdijk, M., Labouriau, R., Victor PMG Rutten Gounder Franken, P., Frijters, A., Nielen, M. and Rutten, V. 2010. Susceptibility to paratuberculosis infection in cattle is associated with single nucleotide polymorphisms in Toll-like receptor 2 which modulate immune responses against Mycobacterium avium subspecies paratuberculosis. Preventive Veterinary Medicine. 93(4):305-315.

Kulig, Hanna., Kmieć, Marek., WojdakMaksymiec, Katarzyna. 2010. Associations between Leptin Gene Polymorphisms and Somatic Cell Count in Milk of Jersey Cows. 79: 237-242.

Kumar, N., Mitra, A., Ganguly, I., Singh, R., Deb, S. M., Srivastava, S. K. and Sharma, A. 2005. Lack of association of brucellosis resistance with (GT) 13 microsatellite allele at 3'UTR of NRAMP1 gene in Indian zebu (Bos indicus) and crossbred (Bos indicus $\times$ Bos taurus) cattle. Vet. Microbiol. 111: 139-143.

Kumar, S., Kumar, S., Singh, R., Chauhan, A., Agrawal, S., Kumar, A., \& Singh, S. 2017. Investigation of Genetic Association of Single Nucleotide Polymorphisms in SP110 Gene with Occurrence of Paratuberculosis Disease in Cattle. International Journal of Livestock Research. 7(3), 81-88.

Lei, W., Liang, Q., Wang, C., Jing, L., Wu, X. and He, H. 2012. BoLA-DRB3 gene polymorphism and FMD resistance or susceptibility in Wanbei cattle. Mol. Biol. Rep. 39: 9203-9209.

Liu, J., T. M. Fujiwara, N. T. Buu, F. O. Sanchez, M. Cellier, A. J. Paradis, D. Frappier, E. Skamene, P. Gros, K. 
Morgan and E. Schurr. 1995. Identification of polymorphisms and sequence variants in the human homologue of the mouse natural resistance associated macrophage protein gene. Am. J. Hum. Genet. 56:845-853.

Macedo, A.A., Costa, E.A., Silva, A.P., Paixão, T.A. and R.L.Santos. 2013. Monocyte-derived macrophages from Zebu (Bos taurus indicus) are more efficient to control Brucella abortus intracellular survival than macrophages from European cattle (Bos taurus taurus).Vet Immunol Immunopathol. 15 (3-4):151.

Maillard, J.C., Chantal, I., Berthier, D. 2001. Sequencing of four new BoLA-DRB3 and six BoLA-DRB alleles. Anim Genet. 32:40-53.

Maillard, J.C., Renard, C., Cardom, P., Chantal, I. and Bensaid, A. 1999. Characterization of 18 new BoLADRB3 alleles. Anim Genet. 30:200 203.

Malo, D., K. Vogan., S. Vidal., J. Hu., M. Cellier., E. Schurr., A. Fuks., N. Bumstead, K. Morgan and P. Gros. 1994. Haplotype mapping and sequence analysis of the mouse Nramp1 gene predict susceptibility to infection with intracellular parasites. Genomics. 23:51-61.

Mantur, B. G. and Amarnath, S. K. 2008. Brucellosis in India - a review; J. Biosci. 33 539-547.

Martinez, M.L., Machado, M.A., Nascimento, C.S., Silva, M.V.G., Teodoro, R.L., Furlong, J., Prata, M.C.A., Campos, A.L., Guimaraes, M.F.M., Azevedo, A.L.S., Pires, M.F.A. and Verneque, R.S. 2006. Association of BoLADRB3.2 alleles with tick (Boophilus microplus) resistance in cattle. Genet. Mol. Res. 5(3): 513-524.
Martinez, R., R. Toro., F. Montoya., M. Burbano., J. Tobón., J. Gallego., S. Dunner and J. Cañón. 2008. Bovine SLC11A1 3' UTR SSCP genotype evaluated by a macrophage in vitro killing assay employing a Brucella abortus strain. Anim. Breed. Genet. 125(4):271-279.

Mishra, C., Kumar, S., Panigrahi, M., Yathish, H.M., Chaudhary, R., Chauhan, A., Kumar, A., Sonawane, A. 2018. Single Nucleotide Polymorphisms in 5' Upstream Region of Bovine TLR4 Gene Affecting Expression Profile and Transcription Factor Binding Sites. Anim Biotechnol. 3;29(2):119-128.

Mrode, R.A,. and G. J. T. Swanson. 1996. Genetic and statistical properties of somatic cell count and its suitability as an indirect means of reducing the incidence of mastitis in dairy cattle. Anim. Breed. Abstr. 64: 847-857.

Nassiry, M.R., Shahroodi, F.E., Mosafer, J., Mohammadi, A., Manshad, E., Ghazanfari, S., Mohammad, Abadi, M.R., and Sulimova, G.E. 2005. Analysis and frequency of bovine lymphocyte antigen (BoLA-DRB3) alleles in Iranian Holstein cattle. Genetika. 41(6):817-822.

Paape, M. J., Shafer-Weaver, K., Capuco, K. Van Oostvel. and Burvenich, C. 2000. Immune surveillance of mammary tissue by phagocytic cells. Adv. Exp. Med. Biol. 480: 259-277.

Paixao, T. A., F. P. Poester., N. A. V. Carvalho., A. M. Borges., A. P. Lage and R. L. Santos. 2007. NRAMP1 3'Untranslated region polymorphisms are not associated with natural resistance to Brucella abortus in cattle. Infect. Immun. 75:2493-2499.

Panei, C.J., Suzuki, K., Echeverria, M.G., Serena, M.S., Metz, G.E. and Gonzalez, E.T. 2009. Association 
of BoLA-DRB3.2 Alleles with Resistance and Susceptibility to Persistent Lymphocytosis in BLV Infected Cattle in Argentina. International Journal of Dairy Science 4(3):123-128

Pant, S, D., Schenkel, F,S., Verschoor, C,P., You,Q. and Kelton,D,F. 2010.A principal component regression based genome wide analysis approach reveals the presence of a novel QTL on BTA7 for MAP resistance in holstein cattle.Genomics. 95: 176-82.

Pant, S. D., Verschoor, C. P., Skelding, A. M., Schenkel, F. S., You, Q., Biggar, G. A., Kelton, D. F., and Karrow, N. A. 2011. Bovine IFNGR2, IL12RB1, IL12RB2, and IL23R polymorphisms and MAP infection status. Mammalian Genome. 22: 583-88.

Paswan, C., Bhushan, B., Patra, B. N., Kumar, P., Sharma, A., Mukherjee, R., Tomar, A.K.S., Dandapat, S. and Dutt, T. 2005. Relationship between the bovine major histocompatibility complex (BoLA) with somatic cell count in crossbred cattle. J. Appl. Anim. Res. 28: 129-132.

Phillips, C.J., Foster, C.R., Morris PA, Teverson R. Genetic and management factors that influence the susceptibility of cattle to Mycobacterium bovis infection. Anim Health Res Rev. 2002; 3:3-13.

Pinedo P J, Buergelt C D, Donovan G A, Melendez P, Morel L, Wu R, Langaee T Y and Rae D O. 2009.Association between CARD15/NOD2 gene polymorphisms and paratuberculosis infection in cattle. Veterinary Microbiology. 134: 346-52.

Pinedo P J, Buergelt C D, Donovan G A, Melendez P, Morel L, Wud R, Langaee T Y and Rae D O. 2009. Candidate gene polymorphisms (BoIFNG, TLR4, SLC11A1) as risk factors for Paratuberculosis infection in cattle. Preventive Veterinary Medicine. 91: 189-96.

Prakash, Chandan., Kumar, Pawan., Joseph, Bincy., Niranjan, A. K., Sharma, Deepak., Chauhan, Anuj., Shukla, S. K. and Verma, Rishendra. 2015. Evaluation of different diagnostic tests for detection of tuberculosis in cattle. Indian Journal of Veterinary Pathology. 39 (1): 1-4.

Prakash, O., Kumar, A., Sonwane, A., Rathore, R., Singh, R.V., Chauhan, A., Kumar, P., Renjith, R., Yadav, R., Bhaladhare, A., Baqir, M. and Sharma, D. 2014. Polymorphism of cytokine and innate immunity genes associated with bovine brucellosis in cattle. Mol. Biol. Rep. 41(5): 28152825.

Ranjan, S. 2014. Genetic Polymorphism and Expression Profiling of Candidate Genes Associated with Mastitis in Crossbred Cattle. Ph.D. Thesis. IVRI (Deemed University), Bareilly, UP, India.

Rawat, K.D., Chaudhary, S., Kumar, N., Gupta, S., Chaubey, K.K., Singh, S.V., Dhama, K., and R. Deb. 2014. Economic losses in a commercial dairy farm due to the outbreak of Johne's disease in India. Res. J. Vet. Pract. 2 (5): 73 - 77.

Rodriguez, A.R., Morales, A.R., Balladares, S., Aguilar, F.H., Vazquez, G.Z. and Gorodezky, C. 2005. Analysis of BoLA Class II microsatellites in cattle infested with Boophilus microplus ticks: Class II is probably associated with susceptibility. Vet. Parasitol. 127(5): 313-321.

Ruiz O, Manzano C, Iriondo M, Juste R A and Estonba A. 2007. Genetic association between bovine NRAMP1 and CARD15 genes and infection by Mycobacterium avium subsp. 
Paratuberculosis. Proceedings of 9I CP.

Rupp R, Hernandez A, Mallard BA. 2007. Association of bovine leukocyte antigen (BoLA) DRB3.2 with immune response, mastitis, and production and type traits in Canadian Holsteins. J Dairy Sci. 90(2):1029-38.

Settle, M., Zanella, R., Mckay, S, D., Schnabel, R.D., Taylor, J.F., Whitlock R, Schukken Y., Van Kessel J.S., Smith J.M. and Neibergs H. 2009. A whole genome association analysis identifies loci associated with Mycobacterium avium subsp. paratuberculosis infection status in US Holstein cattle. Animal Genetics. 40: 655-62.

Sharma BS, Leyva I, Schenkel F, Karrow NA. 2006. Association of toll-like receptor 4 polymorphisms with somatic cell score and lactation persistency in Holstein bulls. J Dairy Sci. 89:36263635

Shukla SK, Shukla S, Chauhan A, Sarvjeet, Khan R, Ahuja A, Singh LV, Sharma N, Prakash C, Singh AV, Panigrahi M. 2017. Differential gene expression in Mycobacterium bovis challenged monocyte-derived macrophages of cattle. Microb Pathog. 113:480-489.

Singh, R., Kumar, S., Deb, R., Sengar, G., Singh, U., Chakraborti, S., Singh, R., Alex, R. and Sharma, S. 2014. Development of a tetra-primer ARMS PCR-based assay for detection of a novel single-nucleotide polymorphism in the 5 untranslated region of the bovine ITGB6 receptor gene associated with foot-and-mouth disease susceptibility in cattle. Arch. Virol. 159: 3385-3389.

Song, Y., Sun, L., Guo, A. and Yang, L. 2014. Toll-like receptor 6 gene polymorphisms increase the risk of bovine tuberculosis in Chinese
Holstein cattle. Acta Histochem. 116(7):1159-62.

Sulabh, Sourabh., Panigrahi, Manjit., Ahmad, Firdous, Sheikh., Varshney, Rajat., Verma, Ankita., Baba, Ahmad, Naseer., Kumar, Satish., Kumari, Soni., Chauhan, Anuj., Kumar, Pushpendra and Bhushan, Bharat. 2018. Peptidoglycan and Lipoteichoic Acid Induces Differential mRNA Response of Immune-Related Genes in PBMC of Crossbred, Tharparkar Cattle and Murrah Buffalo, Animal Biotechnology. DOI: $10.1080 / 1049$ 5398.2018.1461633.

Sun, L., Song, Y., Riaz, H., Yang, H., Hua, G., Guo, A. and Yang, L. 2012. Polymorphisms in toll-like receptor 1 and 9 genes and their association with tuberculosis susceptibility in Chinese Holstein cattle. Vet Immunol Immunopathol. 147(3-4):195-201.

Tosh, K., Campbell, S.J., Fielding, K., Sillah, J., Bah, B. 2006. Variants in the SP110 gene is associated with genetic susceptibility to tuberculosis in West Africa. P Natl Acad Sci USA. 103: 10364-10368.

Tsairidou S., Woolliams J.A., Allen A.R. et al. 2014. Genomic prediction for tuberculosis resistance in dairy cattle. PLoS One, 9, e96728.

Verschoor C P, Pant S D, You Q, Schenkel F S, Kelton, D F and Karrow N A. 2010. Polymorphisms in the gene encoding bovine interleukin-10 receptor alpha are associated with Mycobacterium avium ssp. paratuberculosis infection status. BMC Genetics. 11 (23): 1-9.

Verschoor CP, Pant SD, Biggar GA, Schenkel FS, Sharma BS, Karrow NA. 2012. Identification of SNPs in interferon gamma, interleukin-22, and their receptors and associations with health and production-related traits in 
Canadian Holstein bulls. Anim Biotechnol. 22:7-15.

Wang, X., Xu, S., Gao, X., Ren, H. and Chen, J. 2007. Genetic polymorphism of TLR4 gene and correlation with mastitis in cattle. J. Genet. Genomics. 34(5): 406-412.

Wang, Y., Wang, S., Liu, T., Tu, W., Li, W., Dong, G., Xu, C., Qin, B., Liu, K., Yang, J., Chai, J., Shi, X. and Zhang, Y. 2018. CARD15 Gene Polymorphisms Are Associated with Tuberculosis Susceptibility in Chinese Holstein Cows. PLoS One. 5;10(8)

Xu A, van Eijk MJ, Park C, Lewin HA. 1993. Polymorphism in BoLA-DRB3 exon 2 correlates with resistance to persistent lymphocytosis caused by bovine leukemia virus. J Immunol. 151(12): 6977-85.

Xue, Y., Gao, W.N., Chen, F., Ma, B.B., Zhou, F., Hu, Z.G., Long, T. and Zhao, Z.Q. 2018. CD14 gene polymorphisms associated with increased risk of bovine tuberculosis in Chinese Holstein cows. Vet J. 232:1-5.

Yadav, R., Sharma, A.K., Singh, R., Sonwane, A., Kumar, A., Chauhan, A., Kumar, S., Kumar, T., Renjith, R.,
Bhaladhare, A. and Prakash, O. 2014. An association study of SNPs with susceptibility to Bovine Paratuberculosis infection in cattle. The Indian Journal of Animal Sciences. 84 (5): 16-00.

Yuan, Z., Chu, G., Yang, D., Li, J., Zhang, L., Li, J., Gao, X., Gao, H., Xu, S. and Liu, Z. 2012. BRCA1: A new candidate gene for bovine mastitis and its association analysis between single nucleotide polymorphisms and milk somatic cell score. Mol. Biol. Rep. 39: 6625-6631.

Zanotti M, Poli G, Ponti W, Polli M, Rocchi M, Bolzani E, Longeri M, Russo S, Lewin HA, van Eijk MJ. 1996. Association of BoLA class II haplotypes with subclinical progression of bovine leukaemia virus infection in Holstein-Friesian cattle. Anim Genet. 27(5):337-41.

Zhao, Z., Xue, Y., Hu, Z., Zhou, F., Ma, B., Long, T., Xue, Q. and Liu, H. 2017. Toll-like receptor 2 gene polymorphisms in Chinese Holstein cattle and their associations with bovine tuberculosis. Vet Immunol Immunopathol. $\quad$ 186: 51-54.

\section{How to cite this article:}

Sushil Kumar, Ran Vir Singh, Anuj Chauhan, Arvind Sonwane and Subodh Kumar. 2018. Candidate Gene Polymorphism vis-a-vis Immune Response to Important Infectious Diseases in Bovines. Int.J.Curr.Microbiol.App.Sci. 7(08): 1820-1834. doi: https://doi.org/10.20546/ijcmas.2018.708.209 